\title{
Modeling inherited metabolic disorders of the liver using human induced pluripotent stem cells
}

\author{
S. Tamir Rashid,1,2 Sebastien Corbineau, ${ }^{1,3}$ Nick Hannan,, ${ }^{1}$ Stefan J. Marciniak, ${ }^{2}$ Elena Miranda, ${ }^{2,4}$ \\ Graeme Alexander, ${ }^{5}$ Isabel Huang-Doran, ${ }^{6}$ Julian Griffin, ${ }^{6}$ Lars Ahrlund-Richter, ${ }^{7}$ Jeremy Skepper, ${ }^{8}$ \\ Robert Semple, ${ }^{6}$ Anne Weber, ${ }^{3}$ David A. Lomas, ${ }^{2}$ and Ludovic Vallier ${ }^{1}$

\begin{abstract}
${ }^{1}$ Laboratory for Regenerative Medicine and ${ }^{2}$ Department of Medicine, Cambridge Institute for Medical Research, University of Cambridge, Cambridge, United Kingdom. ${ }^{3}$ INSERM U972, University Paris-Sud, IFR 69, Hôpital du Kremlin-Bicêtre, Le Kremlin-Bicêtre, France.

${ }^{4}$ Department of Cell Biology and Development, Universita' “La Sapienza," Rome, Italy. ${ }^{5}$ Department of Medicine, School of Clinical Medicine, and ${ }^{6}$ University of Cambridge Metabolic Research Laboratories, Institute of Metabolic Science, University of Cambridge, Cambridge, United Kingdom.

7Department of Woman and Child Health, Karolinska Institutet, Stockholm, Sweden. ${ }^{8}$ Department of Physiology, Development and Neuroscience, Multi-Imaging Centre School of Biological Sciences, University of Cambridge, Cambridge, United Kingdom.
\end{abstract}

\begin{abstract}
Human induced pluripotent stem (iPS) cells hold great promise for advancements in developmental biology, cell-based therapy, and modeling of human disease. Here, we examined the use of human iPS cells for modeling inherited metabolic disorders of the liver. Dermal fibroblasts from patients with various inherited metabolic diseases of the liver were used to generate a library of patient-specific human iPS cell lines. Each line was differentiated into hepatocytes using what we believe to be a novel 3-step differentiation protocol in chemically defined conditions. The resulting cells exhibited properties of mature hepatocytes, such as albumin secretion and cytochrome P450 metabolism. Moreover, cells generated from patients with 3 of the inherited metabolic conditions studied in further detail ( $\alpha_{1}$-antitrypsin deficiency, familial hypercholesterolemia, and glycogen storage disease type 1a) were found to recapitulate key pathological features of the diseases affecting the patients from which they were derived, such as aggregation of misfolded $\alpha_{1}$-antitrypsin in the endoplasmic reticulum, deficient LDL receptor-mediated cholesterol uptake, and elevated lipid and glycogen accumulation. Therefore, we report a simple and effective platform for hepatocyte generation from patient-specific human iPS cells. These patient-derived hepatocytes demonstrate that it is possible to model diseases whose phenotypes are caused by pathological dysregulation of key processes within adult cells.
\end{abstract}

\begin{abstract}
Introduction
The possibility of deriving human induced pluripotent stem (iPS) cells by overexpressing just a few transcription factors in somatic cells has opened new opportunities for regenerative medicine and in vitro disease modeling (1). Human iPS cells have since been generated from patients with various diseases (2-4), with several groups reporting disease-specific phenotypes when these cells were subsequently differentiated to neural progenitors $(5,6)$. To our knowledge, however, no human iPS cell-based models have been reported to date for diseases specific to non-neuronal cells (such as cells of mesoderm and endoderm lineages), nor for diseases that arise as a consequence of loss of function that are only seen in fully differentiated adult cells (late-onset diseases). Furthermore, concerns remain that the cellular stresses inherent in reprogramming and differentiation may prevent human iPS cell-derived cell models from preserving the myriad of subtle interactions governing the trafficking and activity of proteins. Understanding these interactions is central to understanding various disease mechanisms and may also provide insights into currently unexplained variations in clinical phenotypes observed between individuals of identical genetic backgrounds (7-9).
\end{abstract}

Authorship note: S. Tamir Rashid and Sebastien Corbineau, as well as Anne Weber and David A. Lomas, contributed equally to this work.

Conflict of interest: The authors have declared that no conflict of interest exists. Citation for this article: JClin Invest. 2010;120(9):3127-3136. doi:10.1172/JCI43122.
These issues are particularly pertinent to the inherited metabolic disorders of the liver (IMDs). This group of diseases results from genetic mutations that affect key proteins within hepatocytes. While IMDs may be treated by whole-organ liver transplant, this procedure carries considerable risk. There is therefore a need for greater understanding of the disease mechanisms and for the development of alternative therapies $(10,11)$. Such investigations are hampered by difficulty in culturing primary hepatocytes and an inability to provide relevant human hepatocyte-like cell lines that faithfully replicate the protein dysfunction and subsequent cellular defects responsible for the disease (12). We report here the generation of a library of human iPS cell lines from individuals with a range of IMDs. A simple, chemically defined culture system for the efficient hepatic differentiation of the new human iPS cell lines was subsequently developed. Finally, by focusing on 3 diseases, we showed that human iPS cell-derived hepatocytes from affected patients successfully recapitulated key features of the cellular pathology seen in the associated diseases, such as aggregation of misfolded mutant $\alpha_{1}$-antitrypsin in the endoplasmic reticulum, deficient LDL receptor-mediated cholesterol uptake, and elevated cellular lipid and glycogen accumulation. These data demonstrate, for the first time to our knowledge, that human iPS cells can be used to model a diverse range of inherited diseases in adult cells. 
Table 1

Characterization of human iPS cell lines

\begin{tabular}{|c|c|c|c|c|c|}
\hline \multirow[t]{2}{*}{ Disease } & \multirow[t]{2}{*}{ Genotype } & \multirow[t]{2}{*}{ Clinical features } & \multicolumn{3}{|c|}{ Human iPS cell lines $(n)$} \\
\hline & & & Derived & Characterized & Differentiated \\
\hline A1ATD & $\begin{array}{l}\text { Homozygous Glu342Lys } \\
\text { (Z mutation) }\end{array}$ & $\begin{array}{l}\text { 65-year-old male of mixed European descent, } \\
\text { liver transplant recipient (patient 1) }\end{array}$ & 9 & 3 & 3 \\
\hline A1ATD & $\begin{array}{l}\text { Homozygous Glu342Lys } \\
\text { (Z mutation) }\end{array}$ & $\begin{array}{l}55 \text {-year-old male of mixed European descent } \\
\text { with clinical symptoms; liver biopsy confirmed intrahepatic } \\
\alpha_{1} \text {-antitrypsin polymer accumulation (patient 2) }\end{array}$ & 8 & 2 & 2 \\
\hline A1ATD & $\begin{array}{l}\text { Homozygous Glu342Lys } \\
\text { (Z mutation) }\end{array}$ & $\begin{array}{l}\text { 16-week-old male of mixed European descent } \\
\text { with liver disease; biopsy confirmed diagnosis }\end{array}$ & 2 & 1 & 1 \\
\hline GSD1a & $\begin{array}{l}\text { Absent hepatic } \\
\text { glucose-6-phosphatase } \\
\text { enzyme }\end{array}$ & $\begin{array}{l}25 \text {-year-old male of mixed European descent } \\
\text { with clinical features of excess glycogen deposition; } \\
\text { confirmed by enzyme functionality assay }\end{array}$ & 6 & 3 & 3 \\
\hline $\mathrm{FH}$ & $\begin{array}{l}\text { Autosomal-dominant } \\
\text { mutation in LDL } \\
\text { receptor }\end{array}$ & $\begin{array}{l}\text { Patient of unknown age and sex with reported symptoms } \\
\text { of early-onset atherosclerotic disease secondary to } \\
\text { hypercholesterolemia and strong family history; } \\
\text { diagnosis confirmed by LDL receptor dysfunction assay }\end{array}$ & 9 & 3 & 1 \\
\hline $\begin{array}{l}\text { Crigler-Najjar } \\
\text { syndrome }\end{array}$ & $\begin{array}{l}\text { Homozygous for } 13-b p \\
\text { deletion, exon } 2 \text { of } U G T 1 A 1\end{array}$ & $\begin{array}{l}\text { 2-month-old male of mixed European descent } \\
\text { with clinical features of disease }\end{array}$ & 6 & 3 & 1 \\
\hline $\begin{array}{l}\text { Hereditary } \\
\text { tyrosinemia type } 1\end{array}$ & 2 alleles $^{A}$ & $\begin{array}{l}\text { 2-month-old male of mixed European descent } \\
\text { with clinical features of disease }\end{array}$ & 6 & 3 & 1 \\
\hline Contro|B & Not tested & Asymptomatic & 15 & 8 & 8 \\
\hline
\end{tabular}

AOne allele carries a missense mutation in codon 166 of fumarylacetoacetate hydrolase (FAH) gene: T>G in base 553 (553T>G) causes a Val166Gly substitution; the other allele is unknown. ${ }^{B}$ In total, 3 control patients were included; iPS cell line data are summed for all controls.

\section{Results}

\section{Generation of a buman iPS cell library from patients with IMDs}

Dermal fibroblasts were obtained from skin biopsies from 7 individuals with a range of IMDs and from 3 healthy controls (20 human iPS cell lines, 5 diseases; Table 1 and Supplemental Table 1; supplemental material available online with this article; doi:10.1172/JCI43122DS1). These somatic cells were then reprogrammed to pluripotent stem cells using the 4-factor approach developed by Yamanaka and colleagues (13). The success rate of human iPS cell derivation was extremely variable, ranging from $0.01 \%$ to $0.1 \%$ for each individual, confirming the existent variability in capacity to reprogram dermal fibroblasts from patients of different age and sex. Where possible, 3 human iPS cell lines per individual were subsequently used for further analyses in order to define the conserved variability in differentiation capacity between lines derived from the same individual. The resulting library of human iPS cell lines - 20 lines from 10 individuals - were characterized for their morphology, expression of pluripotency markers, capacity to form derivatives of the 3 germ layers in vivo and in vitro, normal karyotype, and expression profiles of endogenous and exogenous pluripotency genes (Supplemental Figure 1, A-F). All the human iPS cells expressed endogenous markers of pluripotency and were able to differentiate into neuroectoderm, endoderm, and mesoderm cells (Supplemental Figure 1, B-D and F, and data not shown), confirming successful generation of pluripotent stem cells from somatic cells. Interestingly, none of the human iPS cell lines lacked the ability to differentiate into 1 specific germ layer, showing the absence of strong variability in the capacity of differentiation of the human iPS cell lines generated for this study. Furthermore, abnormal karyotype was only observed in human iPS cells grown for long periods of time (i.e., passage 40) in chemically defined conditions. This suggests that the culture system used to expand human iPS cells can affect their genetic stability, as had been described for human ES cells (14). Therefore, only early-passage human iPS cells (i.e., before passage 30 ) were used for the present study. The number of viral integrations was variable between lines and patients (data not shown), reinforcing previous studies showing that full reprogramming is not associated with a specific pattern of viral integration (15). Finally, ectopic expression of exogenous transgenes was rarely detected in our human iPS cells lines (Supplemental Figure 1F), demonstrating the efficiency of our viral vector to be silenced in pluripotent stem cells. Collectively, these results demonstrate that the human iPS cell lines generated for this study were fully reprogrammed and thus represent what we believe to be a unique library of human iPS cell lines derived from patients with IMDs.

\section{Development of a robust and simple method to generate bepatocytes from patient-specific human iPS cells}

We have recently developed a robust protocol to differentiate human ES and normal human iPS cells into hepatocytes (16). This culture system provided the basis for a method of differentiation optimal for use with patient-specific iPS cells. Our main objective was to develop a simple method that could effectively differentiate a broad number of human iPS cell lines into hepatocytes. Human iPS cell lines derived from healthy individuals ( 6 lines, $n=2$ subjects) and individuals with $\alpha_{1}$-antitrypsin deficiency (A1ATD; 6 lines, $n=3$ subjects) were used to empirically screen a wide range of culture conditions. The 3 -step protocol shown in Figure 1 follows the key stages of the natural pathway of hepatocyte development. The first step consisted of driving human iPS cells to endoderm cells expressing Sox17, CXCR4, foxA2, and Hex, a specific marker of anterior definitive endoderm from which liver cells are generated 
A

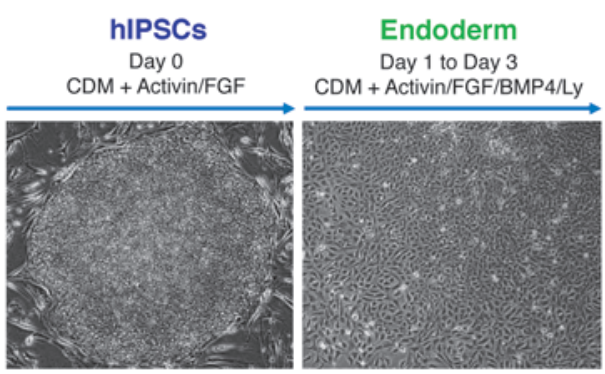

Hepatic specification Hepatocyte maturation

Day 4 to Day 8

Day 9 to Day 25

RPMI + Activin Maturation medium + HGF + OSM
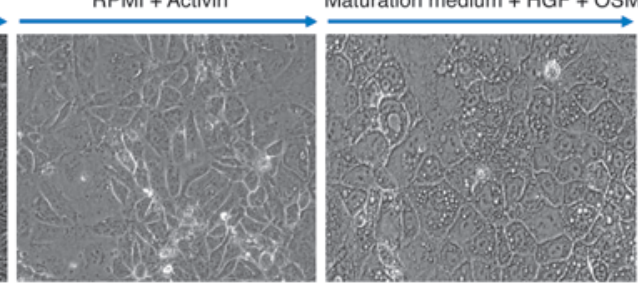

B
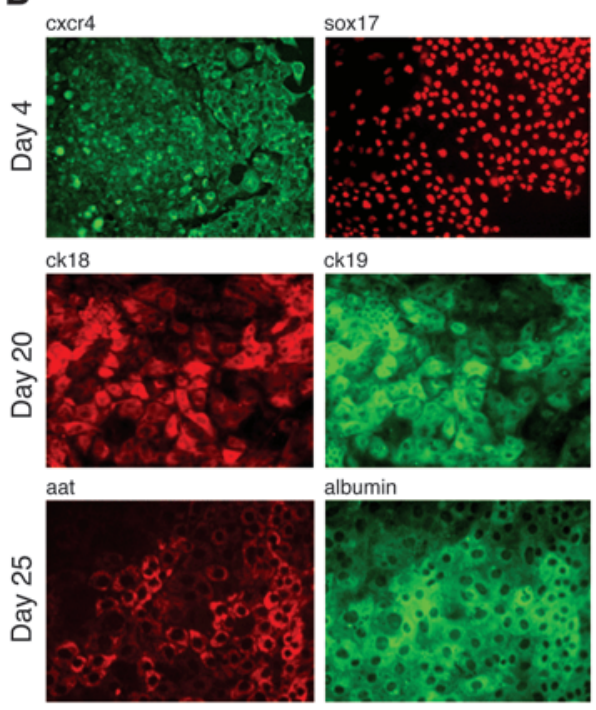

ck19

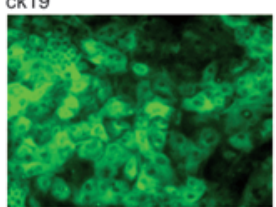

albumin
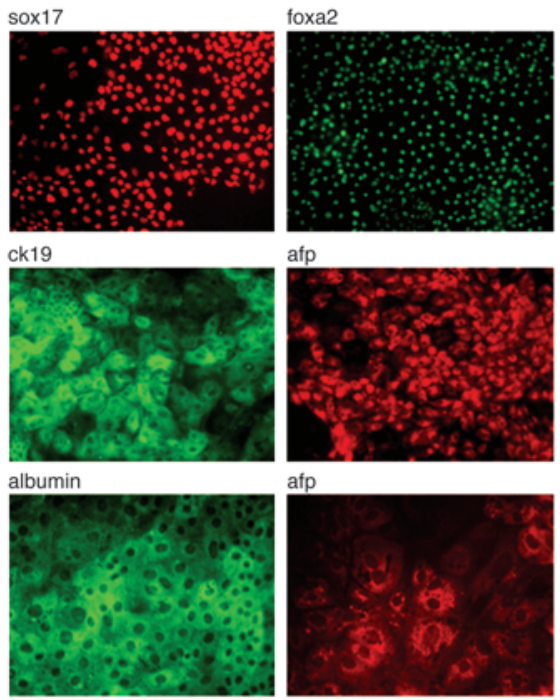

afp

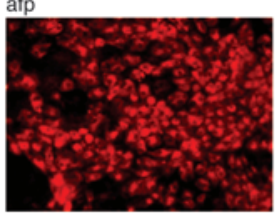

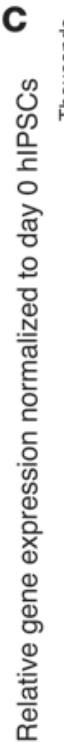

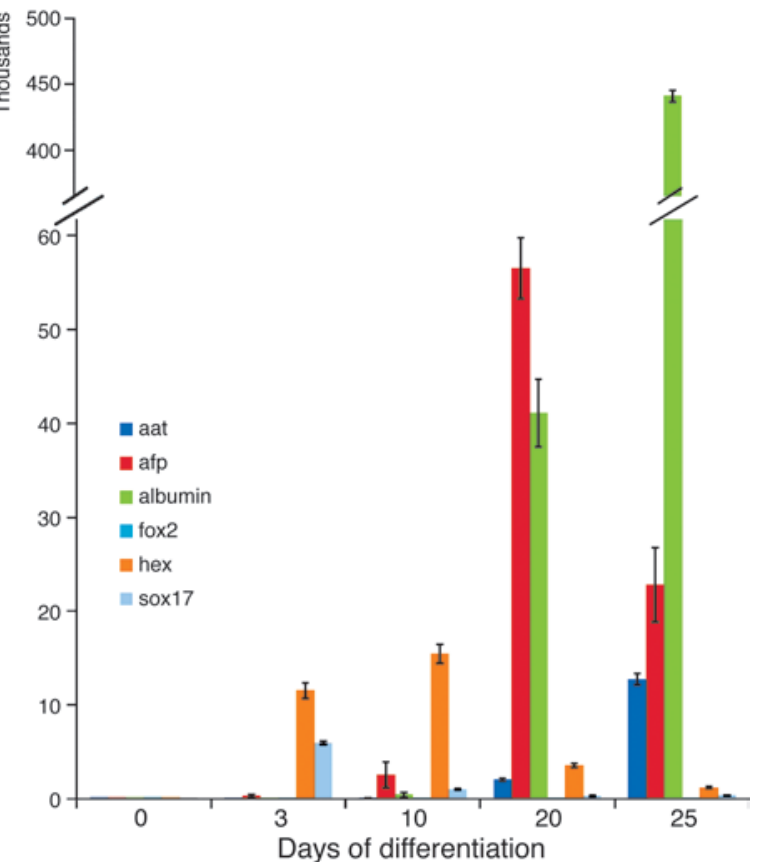

D

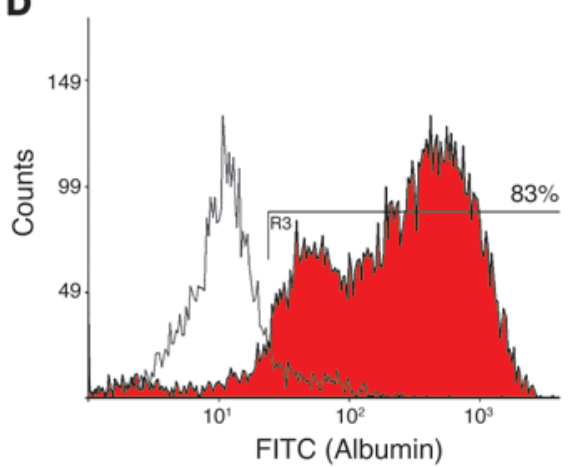

$\mathbf{E}$

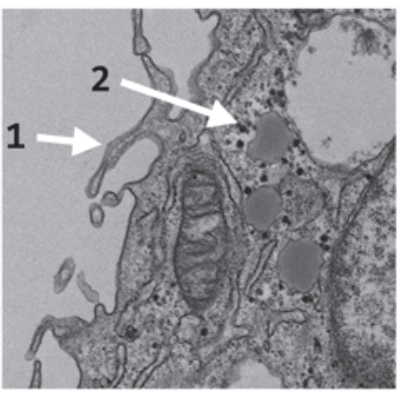

\section{Figure 1}

Generation of hepatocytes from disease-specific human iPS cells. (A) Protocol used to differentiate the disease-specific human iPS cell library into hepatocytes. (B) Immunostaining analyses for expression of the indicated proteins marking key stages of hepatocyte development (day 4, endoderm; day 20, hepatic progenitor; day 25, fetal hepatocyte). (C) Real-time PCR analysis for expression of genes marking key stages of diseasespecific human iPS cell (hIPSC) differentiation to hepatocytes. Error bars denote SEM. (D) Fraction of cells expressing albumin after 25 days of hepatic differentiation, as shown by FACS analyses. (E) Morphologic analysis of disease-specific human iPS cell-derived hepatocytes (day 25) by transmission EM, showing the presence of apical microvilli and glycogen rosettes (numerals 1 and 2, respectively). Original magnification, $\times 20$ (A); $\times 40(B) ; \times 3,000(E)$. The data shown were taken from 1 line (patient 1 ; line 1), but are representative of all lines similarly characterized (Table 1 ).

(Figure 1, B and C), using chemically defined medium containing polyvinyl alcohol (CDM-PVA medium) supplemented with activin, FGF2, BMP-4, and a PI3K inhibitor. The resulting endoderm cells were then differentiated into hepatic progenitors expressing AFP,
CK18, CK19, HNF4, and HNF6 (Figure 1, B and C, and Supplemental Figure 2, A-C) using activin and B27 supplement. Finally, maturation in a CMRL/hepatocyte culture medium mix supplemented with HGF and Oncostatin-M yielded hepatocyte-like cells 
A

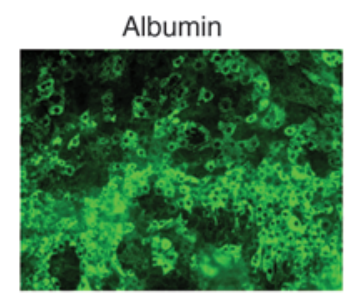

Albumin secretion

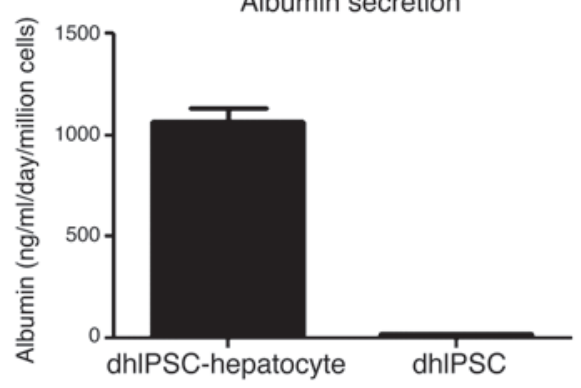

B
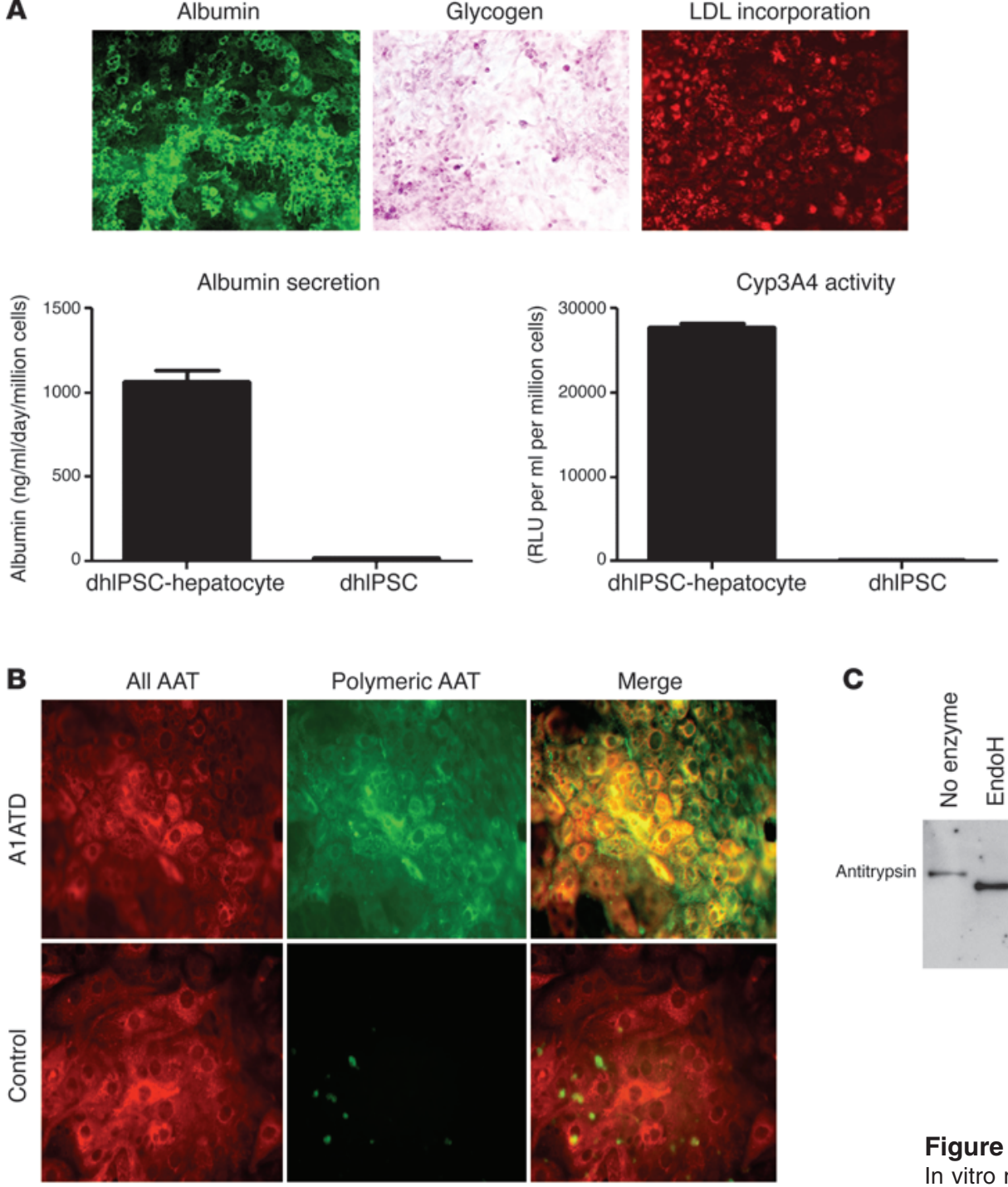
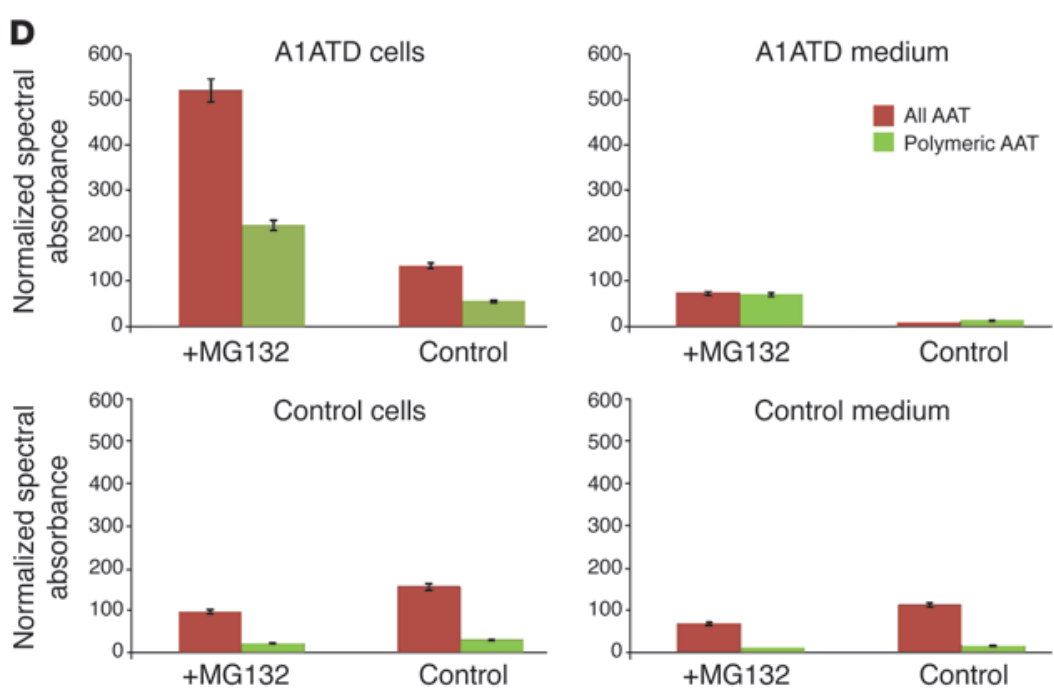
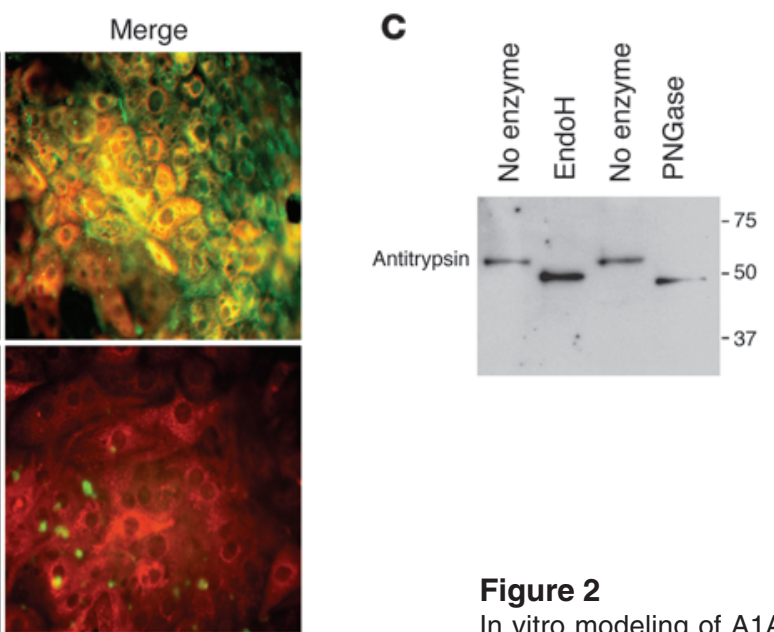

\section{Figure 2}

In vitro modeling of A1ATD using disease-specific human iPS cells. (A) A1ATD disease-specific human iPS cells (dhIPSCs) differentiated to hepatocytes displayed functional activity characteristic of primary human hepatocytes, including the presence of intracellular albumin, glycogen storage (shown by PAS staining), LDL cholesterol uptake (shown by fluoresceinated LDL incorporation), albumin secretion, and active CytP450 metabolism. Error bars denote SEM. (B) Immunostaining analyses for expression of misfolded polymeric $\alpha_{1}$-antitrypsin using the polymer-specific 2C1 antibody (green) or an antibody that detects all forms of $\alpha_{1}$-antitrypsin (red) in A1ATD patient-specific and control human iPS cell-derived hepatocytes. Merged images are shown at right. (C) Endoglycosidase $\mathrm{H}$ (EndoH) digestion of A1ATD disease-specific human iPS cell-derived hepatocyte microsomal subcellular fraction, confirming retention of misfolded polymeric $\alpha_{1}$-antitrypsin protein within the endoplasmic reticulum. $n=3$. (D) ELISA to assess the intracellular expression (cells) and secretion (medium) of all $\alpha_{1}$-antitrypsin and polymeric $\alpha_{1}$-antitrypsin protein in A1ATD patient-specific and control human iPS cell-derived hepatocytes after overnight proteasomal inhibition by MG132. Error bars denote SEM. $n=3$. Original magnification, $\times 20(A) ; \times 40(B)$. 
expressing both albumin and $\alpha_{1}$-antitrypsin by day 25 (Figure 1 , B-D). FACS analyses showed that greater than $80 \%$ of the cells generated in these culture conditions expressed albumin (Figure 1D), confirming the homogeneity of the cell population generated with this approach. By day 25, the cells showed a strong morphological resemblance to human hepatocytes, displaying occasional binucleity (Figure 1A), glycogen deposits, and apical microprotrusions (Figure 1E) as well as rough and smooth ER and a prominent Golgi body (Supplemental Figure 2E). In addition, the human iPS cell-derived hepatocytes shared in vitro functional characteristics with native human hepatocytes in that they were able to store glycogen and LDL, secrete albumin, metabolize drugs via the CytP450 pathway (Figure 2A and Supplemental Figure $2 \mathrm{H}$ ), and express GFP protein under the control of the hepatocyte-specific ApoAII promoter (Supplemental Figure 2D). Furthermore, the expression of exogenous reprogramming factors remained suppressed in these cells, confirming that the retroviral transgenes stayed silenced after differentiation (Supplemental Figure 2F). Although these data provide considerable evidence showing relevant functional characteristics of the liver cells generated in our culture system, we acknowledge that these cells were not terminally differentiated, as evidenced by their continued expression of AFP (Figure 1, B and C). Instead, these hepatocytes are likely to be developmentally located somewhere between the end of the first trimester of fetal embryonic development and fully adult cells, as displayed by their $\alpha_{1}$-antitrypsin gene expression levels and percentage of albumin-expressing cells seen by FACS (Figure 1D, Supplemental Figure 1G, and Supplemental Figure 3B). Finally, we note that this culture system was applied to a large number of lines, 20 derived from 10 individuals, and only 2 human iPS cell lines were unable to differentiate into liver cells (Supplemental Figure 2, $\mathrm{C}$ and $\mathrm{H}$ ). Collectively, these results demonstrate the efficiency of our defined culture conditions for driving differentiation of human iPS cells to near-homogenous populations of fetal hepatic cells displaying some functional characteristics specific to mature hepatocytes.

\section{In vitro modeling of liver diseases using patient-specific buman iPS cells}

A1ATD. The validity of our approach to model liver disease in vitro was assessed by investigating whether disease-specific human iPS cell-derived hepatocytes replicated key features of the diseases from which they were derived. We first focussed on A1ATD diseasespecific human iPS cells. Previous studies have shown that the $Z$ allele (Glu342Lys) results in the formation of ordered polymers of $\alpha_{1}$-antitrypsin that are retained within the ER (17). These polymers accumulate within hepatocytes, predisposing the homozygote to neonatal hepatitis, cirrhosis, and hepatocellular carcinoma (18). This pathway of $\alpha_{1}$-antitrypsin polymerization is central to the clinical phenotype (17). We therefore used the $2 \mathrm{C} 1$ polymer specific monoclonal antibody (19) to detect polymers within A1ATD disease-specific human iPS cell-derived hepatocytes. Polymers were detected by immunostaining and by ELISA analyses (Figure 2, B and D, and Supplemental Figure 2G). These data showed that accumulation of $\alpha_{1}$-antitrypsin polymers only occurred in disease-specific human iPS cell-derived hepatocytes from individuals with A1ATD; no polymers were present in human iPS cell-derived hepatocytes from control subjects. The cellular localization of the polymers was confirmed by subcellular fractionation of the cells, followed by digestion with endoglycosidase $\mathrm{H}$ (Figure 2C and Supplemental Figure $3 \mathrm{C}$ ), an enzyme that removes $N$-linked glycans still in the high mannose ER form but does not affect oligosaccharide chains after the addition of sialic acid in the Golgi apparatus. Endoglycosidase $\mathrm{H}$ treatment reduced all intracellular $\alpha_{1}$-antitrypsin in the diseasespecific but not control human iPS cell-derived hepatocytes to a single 50-kDa band, demonstrating that all such intracellular $\alpha_{1-}$ antitrypsin was retained within the ER. Importantly, the observed increase in polymer was consistent among 3 different iPS cell lines taken from the same patient, but varied among iPS cell lines taken from different patients (Supplemental Figure 2G). This phenotypic variability could correlate with the disease status in the patient and thus could reflect a clinical feature of this disease. However, a low level of polymer expression was observed in human iPS cell lines derived from A1ATD patient 2, which were also particularly resistant to endoderm differentiation (Supplemental Figure 2C). Therefore, variability in disease phenotype observed in this study mainly reflects the capacity of human iPS cells to achieve efficient hepatic differentiation. Finally, to investigate the potential application of this cell line for future in vitro drug screening, we assessed the effects of adding the proteasome inhibitor MG132 to the medium overnight. Blockage of this important protein degradation pathway revealed a disease-specific intracellular increase in $\alpha_{1}$-antitrypsin polymers (Figure 2D). Taken together, these results demonstrated that disease-specific human iPS cell-derived hepatocytes are capable of modeling key pathological feature of A1ATD in vitro and may also prove useful for future drug screening assays.

$F H$. To confirm the ability of our culture system to model clinical disease, and to investigate its potential for studying disease processes specific to other subcellular locations (Supplemental Figure $3 \mathrm{~A}$ ), we characterized the disease-specific human iPS cell-derived hepatocytes from 1 individual with familial hypercholesterolemia (FH). The primary defect in $\mathrm{FH}$ is impaired functioning of the LDL receptor, resulting in an excess of plasma LDL and premature atheromas (20). Disease-specific human iPS cell lines generated from the individual with $\mathrm{FH}$ were differentiated into hepatocytes displaying typical functional characteristics (Figure 3A). Western blot analysis of the differentiated cells confirmed the absence of the LDL receptor (Supplemental Figure 3E). The in vivo functional implications of this receptor deficiency were also conserved in our model, as shown by immunostaining and FACS analysis demonstrating that FH disease-specific human iPS cell-derived hepatocytes had an impaired ability to incorporate LDL (Figure 3B). These results demonstrated that disease-specific human iPS cells can successfully be used to model FH and may therefore be suitable for modeling other diseases involving transmembrane protein trafficking and receptor dysfunction.

GSD1a. Finally, we used our approach to model a condition representative of impaired cytosolic metabolism. Glycogen storage disease type 1a (GSD1a) is caused by a deficiency in glucose6-phosphatase, the main enzyme catalyzing the hydrolysis of glucose-6-phosphate to glucose and phosphate, the terminal steps in gluconeogenesis and glycogenolysis. Individuals with GSD1a cannot maintain glucose homeostasis and experience hyperlipidemia, lactic acidosis, hyperuricemia, hypoglycemia, hepatomegaly, kidney enlargement, and growth retardation (21). We differentiated 3 GSD1a lines from 1 subject, and the resulting cells were characterized for their hepatocyte-like nature (Figure 4A and Supplemental Figure 3F). Period acid Schiff(PAS) staining revealed the GSD1a disease-specific human iPS cell-derived hepatocytes accumulated substantially greater amounts of intracellular glycogen than did those of controls (Figure 4B), confirming the cellular disease phenotype. 


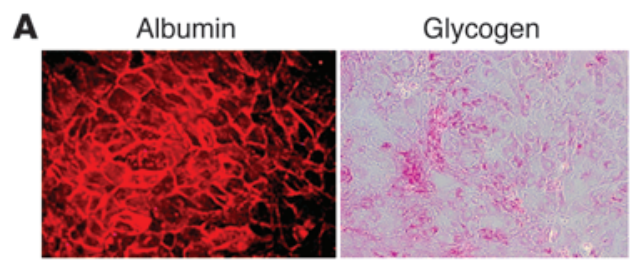

Albumin secretion
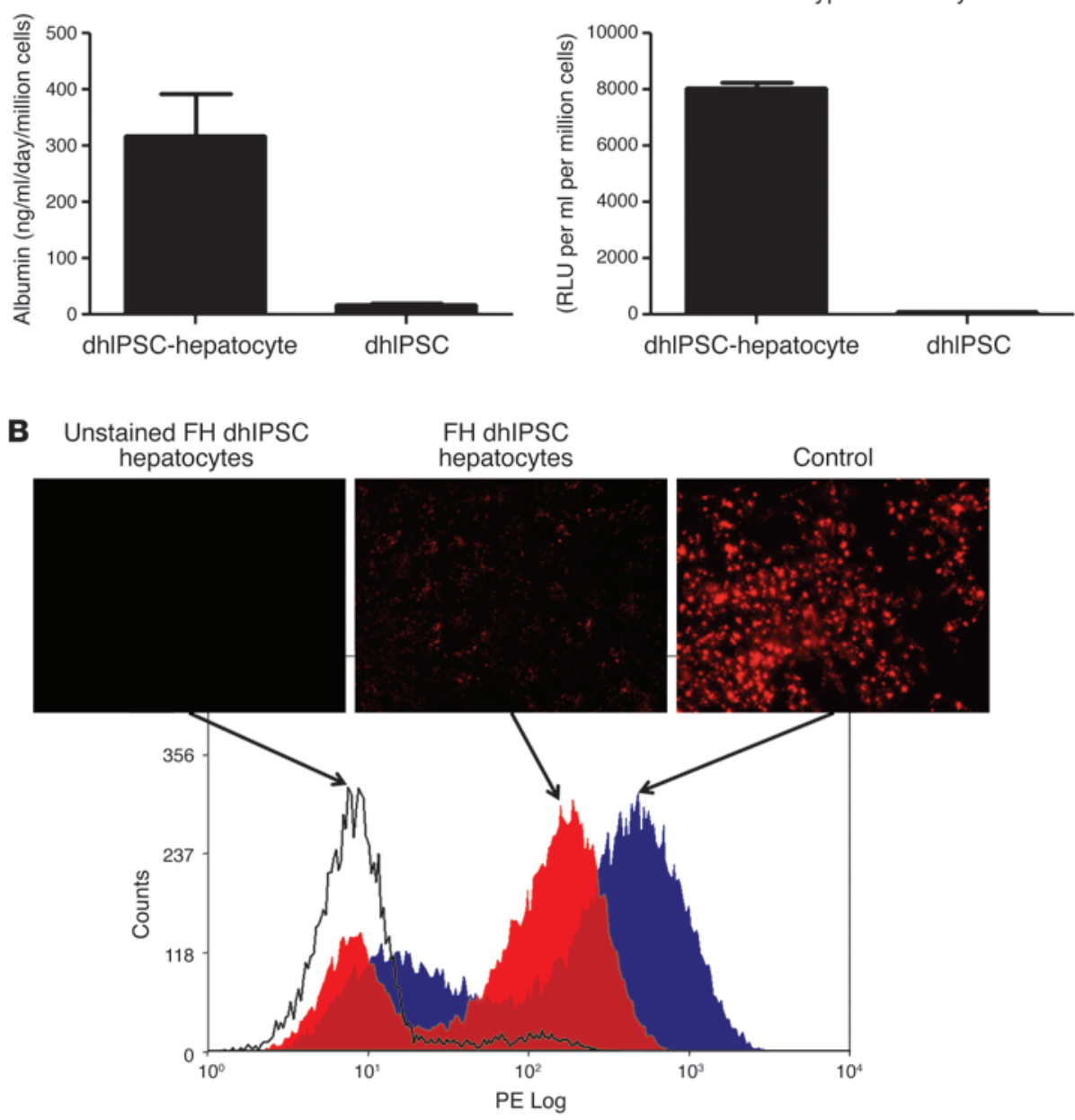

\section{Figure 3}

In vitro modeling of $\mathrm{FH}$ using diseasespecific human iPS cells. (A) FH disease-specific human iPS cells differentiated to hepatocytes displayed functional activity characteristic of primary human hepatocytes, including intracellular presence of albumin, glycogen storage, albumin secretion, and active CytP450 metabolism. Error bars denote SEM. (B) FACS analysis for fluoresceinated LDL incorporation confirmed $\mathrm{FH}$ disease-specific human iPS cell-derived hepatocytes (red curve) lacked the ability to efficiently take up LDL compared with the positive control (blue curve). Human iPS cells grown in the absence of LDL were used as a negative control (unstained; black curve). Original magnification, $\times 40(A) ; \times 20(B)$.
In addition, the same cells also replicated other features of the disease, such as excessive lipid accumulation and excessive production of lactic acid (Figure 4, C and E). Critically, the cells induced expression of 3 canonical glucagon-responsive genes after glucagon stimulation (Figure 4D and refs. 22, 23). These results demonstrated not only that key cellular aspects of GSD1a can be modeled in vitro, but also that the hepatocytes generated in our culture system display at least some responsiveness to a key hormone of intermediary metabolism, which suggests that our approach may therefore be applied to model other, more common metabolic disorders.

\section{Discussion}

Patient-specific disease modeling using human iPS cells has to date proven possible for a limited number of very rare neurodevelopmental disorders. By developing a simple chemically defined culture system permitting efficient differentiation of numerous human iPS cell lines toward cells of a mature hepatic state, we now demonstrate the pos- sibility of modeling groups of diseases of non-neuronal origin whose phenotypes are a consequence of complex protein dysregulation within adult cells. The 3 diseases we modeled cover a diverse range of pathological mechanisms, from protein misfolding in the ER to cell surface receptor dysfunction and finally to obstruction of cytosolic metabolism, thereby demonstrating the potentially wide applications for exploitation of this platform into other research areas.

The potential of our modeling system is best exemplified by first considering the most common and well-characterized disorder from our group of diseases, A1ATD. Previous studies have demonstrated that misfolding and entrapment of the $Z$ polymers within the ER is the underlying mechanism for the clinical phenotype (17). However, the variation in phenotype displayed among individuals with the same genotype has not yet been explained. Such variations may be caused by different patients' capacities to handle misfolded proteins $(7-9,18,24,25)$. The hepatocyte-specific quality control mechanisms responsible for processing such 

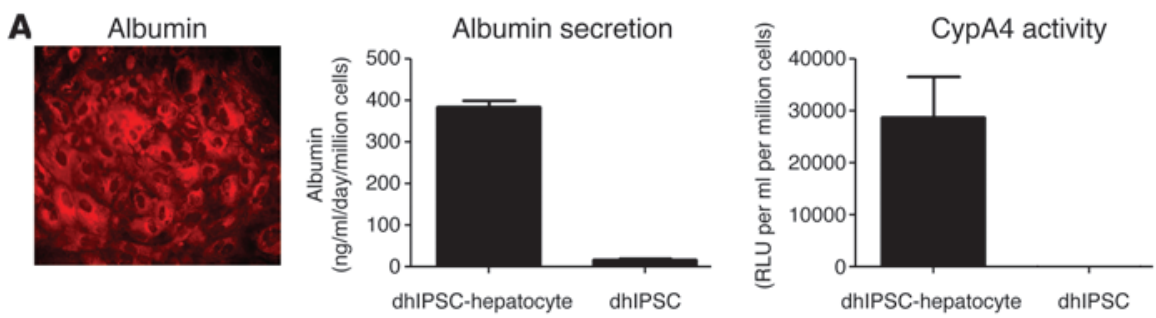

$\mathbf{B}$
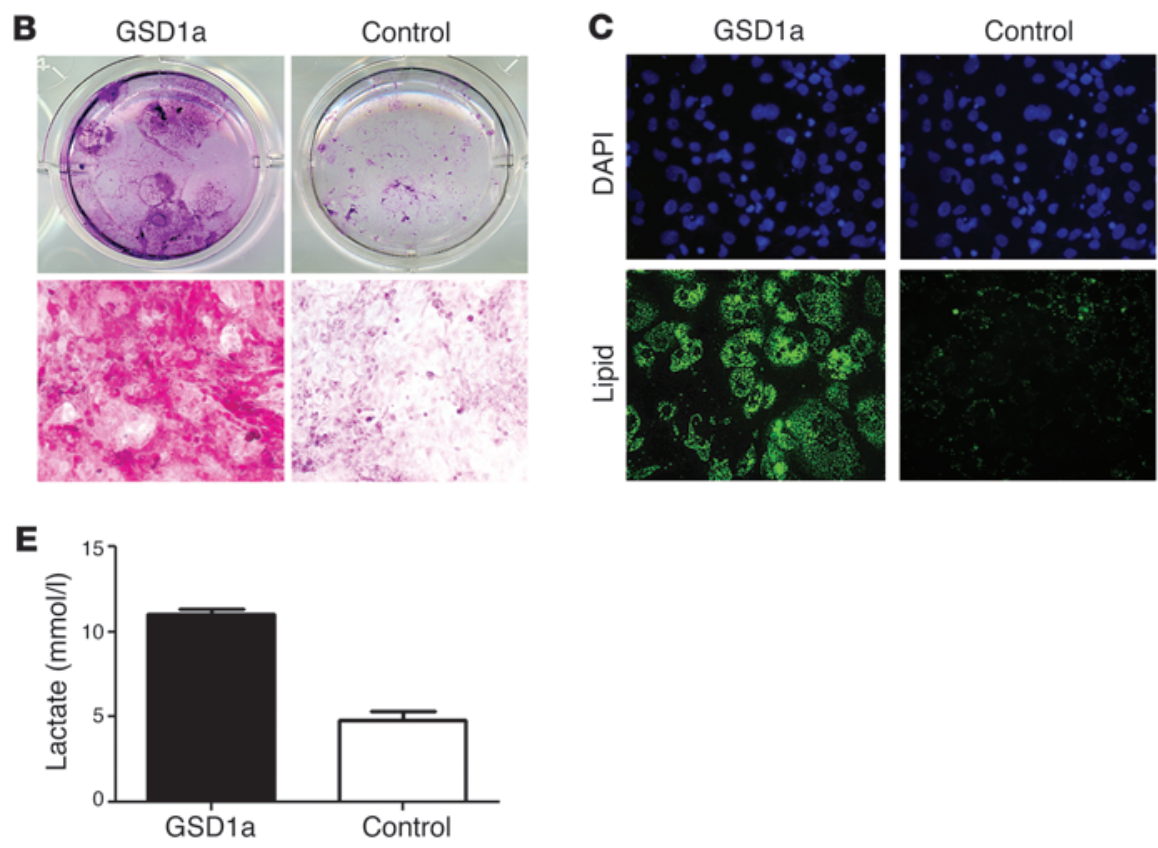

Figure 4

In vitro modeling of GSD1a using disease-specific human iPS cells. (A) GSD1a disease-specific human iPS cells differentiated to hepatocytes displayed functional activity characteristic of primary human hepatocytes, including intracellular presence of albumin, albumin secretion, and active CytP450 metabolism. Error bars denote SEM. (B) PAS staining showing excessive accumulation of intracellular glycogen in GSD1a disease-specific human iPS cell-derived hepatocytes compared with human iPS cell-derived hepatocytes from control subjects. $n=3$. (C) BODIPY staining showed excessive accumulation of intracellular lipid in GSD1a disease-specific human iPS cell-derived hepatocytes compared with human iPS cell-derived hepatocytes from control subjects. $n=3$. (D) Disease-specific human iPS cell-derived hepatocytes appropriately upregulated transcriptional targets of glucagon, as shown by quantitative RT-PCR analysis of PEPCK, glucose-6-phosphatase (G6P), and IGFBP1 expression analyzed 0, 1, 2, and 3 hours after stimulation with $100 \mathrm{nM}$ glucagon hydrochloride. Error bars denote SEM. $n=3$. (E) GSD1a disease-specific human iPS cell-derived hepatocytes secreted more lactate than did human iPS cell-derived hepatocytes from control subjects, as assessed by ELISA analysis of a 24-hour collection of cell culture medium. Error bars denote SEM. $n=3$. Original magnification, $\times 40$ (A; B, bottom; and C).

proteins are now being elucidated $(26,27)$. Although one such pathway, that of the proteasome, has an important role in metabolizing $Z \alpha_{1}$-antitrypsin in some hepatic (28) and extrahepatic mammalian cell lines (29), it can only approximate protein handling in the proteasome of the human hepatocyte. Furthermore, despite our increased understanding of the protein degradation pathway, it still remains unclear how accumulation of $Z \alpha_{1}$-antitrypsin causes cell death and liver failure. In order to enhance our understanding of this and other related mechanisms critical to the etiology of similar protein misfolding disorders, elucidation of the protein degradation pathways specific to human hepatocytes is a crucial next stage of investigation. By generating patient-specific iPS cell-derived hepatocytes capable of conserving core elements of disease-specific protein polymerization and ER entrapment, we showed that such subtle intracellular processes can potentially be studied with the in vitro cellular system described herein. Our data also suggest that the same intracellular processes can be accurately preserved despite the highly stressful implications that ex vivo reprogramming and differentiation protocols may exert upon the cells $(8,25)$. However, it should be noted that before comparative patient-specific human iPS cell-based studies are performed, clearly defined criteria will need to be agreed upon to assure that investigators have achieved a sufficient level of cellular differentiation. Our data, although limited to hepatocyte differentiation, suggest that individuals of differing genetic backgrounds host intrinsic variance in the capacity of their human iPS cells to achieve in vitro differentiation toward adult cells. Therefore, any phenotypic variance observed in vitro between lines originating from different patients will need to be confirmed with large numbers of replicate patient samples to ensure that such observations do not simply reflect each line's varied capacity of differentiation toward a given cell of interest. 


\section{Table 2}

Primer sequences

\begin{tabular}{|c|c|}
\hline Primer & Sequence \\
\hline Exogenous hOCT4, forward & 5'-ССТСАСTTCACTGCACTGTA-3' \\
\hline Exogenous hOCT4, reverse & 5'-TCCTGTCTTTAACAAATTGGACT-3' \\
\hline Exogenous hKLF4, forward & 5'-GATGAACTGACCAGGCACTA-3' \\
\hline Exogenous hKLF4, reverse & 5'-TCCTGTCTTTAACAAATTGGACT-3' \\
\hline Exogenous hSOX2, forward & 5'-CCCAGCAGACTTCACATGT-3' \\
\hline Exogenous hSOX2, reverse & 5'-TCCTGTCTTTAACAAATTGGACT-3' \\
\hline Exogenous hMYC, forward & 5'-AAGAGGACTTGTTGCGGAAA-3' \\
\hline Exogenous hMYC, reverse & 5'-TCCTGTCTTTAACAAATTGGACT-3' \\
\hline Endogenous hOCT4, forward & 5'-CCTCАСTTCACTGCACTGTA-3' \\
\hline Endogenous hOCT4, reverse & 5'-CAGGTTTTCTTTCCCTAGCT-3' \\
\hline Endogenous hKLF4, forward & 5'-GGTCGGACCACCTCGCCTTACAC-3' \\
\hline Endogenous hKLF4, reverse & 5'-CTCAGTTGGGAACTTGACCA-3' \\
\hline Endogenous hSOX2, forward & 5'-ATGTCCCAGCACTACCAGAG-3' \\
\hline Endogenous hSOX2, reverse & 5'-GCACCCCTCCCATTTCCC-3' \\
\hline Endogenous hMYC, forward & 5'-CTGAAGAGGACTTGTTGCGGAAAC-3' \\
\hline Endogenous hMYC, reverse & 5'-TCTCAAGACTCAGCCAAGGTTGTG-3' \\
\hline NANOG, forward & 5'-CATGAGTGTGGATCCAGCTTG-3' \\
\hline NANOG, reverse & 5'-CCTGAATAAGCAGATCCATGG-3' \\
\hline S0X17, forward & 5'-CAGTGACGACCAGAGCCAGACC-3' \\
\hline SOX17, reverse & 5'-CCACGACTTGCCCAGCATCTT-3' \\
\hline FOXA2, forward & 5'-ACTCGCTCTCCTTCAACG-3' \\
\hline FOXA2, reverse & 5'-CCTGGTAGTAGGAGGTATCTGC-3' \\
\hline PBGD, forward & 5'-GGAGCCATGTCTGGTAACGG-3' \\
\hline PBGD, reverse & 5'-CCACGCGAATCACTCTCATCT-3' \\
\hline HEX, forward & 5'-CACCCGACGCCCTTTTACAT-3' \\
\hline HEX, reverse & 5'-GAAGGCTGGATGGATCGGC-3' \\
\hline AFP, forward & 5'-AGAACCTGTCACAAGCTGTG-3' \\
\hline AFP, reverse & 5'-TGGTAGCCAGGTCAGCTAAA-3' \\
\hline ALBUMIN, forward & 5'-CCTTTGGCACAATGAAGTGGGTAACC-3' \\
\hline ALBUMIN, reverse & 5'-GACAGCAAGCTGAGGATGTC-3' \\
\hline AAT, forward & 5'-AGACCCTTTGAAGTCAAGCGACC-3' \\
\hline AAT, reverse & 5'-CCATTGCTGAAGACCTTAGTGATGC-3' \\
\hline CYP3A4, forward & 5'-TGTGCCTGAGAACACCAGAG-3' \\
\hline CYP3A4, reverse & 5'-GTGGTGGAAATAGTCCCGTG-3' \\
\hline ApoA2, forward & 5'-GGAGAAGGTCAAGAGCCCAGAG-3' \\
\hline ApoA2, reverse & 5'-AGCAAAGAGTGGGTAGGGACAG-3' \\
\hline LDLR, forward & 5'-GGGCGTGAAATTGCGCTGGACCGTC-3' \\
\hline LDLR, reverse & 5'-TCACAGACGAACTGCCGAGAGATGC-3' \\
\hline
\end{tabular}

The 2 other diseases subsequently assessed with our modeling system reinforced the demonstration that downstream effects of protein dysfunction in hepatocytes were conserved in a patientspecific manner using disease-specific human iPS cells. By replicating the lack of LDL receptor-mediated uptake of LDL lipid into hepatocytes, we successfully established a cell model for FH. The FH model illustrates how this platform is uniquely equipped to provide a holistic impression of the hepatocyte-specific native processes governing receptor dysfunction, from nuclear synthesis to trafficking through the ER to recycling at the cell membrane. We therefore suggest that this platform may be well-suited for further follow-up studies into a broad range of liver-related receptoropathies.

Finally, by demonstrating the conservation of several key facets of the GSD1a cellular phenotype and the hepatocyte-specific, glucagon-induced upregulation of key downstream gluconeogenic enzymes and a secreted IGF1 binding protein, we provided proof of concept that similar studies to investigate other more common metabolic disorders could be feasible with this platform. These dis- eases have suffered from shortcomings of currently available in vitro cell models unable to simulate some of the key hepatocyte processes that go awry in disease. The use of patient-specific human iPS cell lines in our system could permit modeling of such disease processes within a context of well-characterized genetic and clinical profiles, therefore offering exciting opportunities for cellular dissection of these diseases.

In conclusion, we believe the present study has advanced the human iPS cell field in several ways. First, demonstration of the possibility of modeling different diseases affecting adult cells using a single platform has answered one of the most pressing questions in the human iPS cell-disease modeling field. This realization has accordingly allowed us to provide other investigators with a robust and easily reproducible technical resource for potential application into diverse fields of research. Second, by demonstrating that human iPS cell-derived hepatocytes can be generated from multiple patients of varied genetic and disease backgrounds, we propose our system as an efficient methodology, which we believe to be new, for the early-stage safety and therapeutic screening of liver-targeted compounds of potential relevance to the pharmaceutical industry. Finally, and perhaps most importantly, demonstrating the ability to homogenously derive large numbers of patient-specific hepatocytes from a group of diseases ideal for cell-based therapy raises the possibility that we have taken another step toward realizing the ultimate goal of patient-specific human iPS cell technology.

\section{Methods}

Human iPS cell derivation and culture. Following appropriate ethical approval and patient consent, 8-mm skin punch biopsies were obtained from volunteering patients attending Addenbrooke's Hospital (ethics reference no. 08/H0311/201; R\&D no. A091485). Fibroblasts were derived from the donated tissue in GMP conditions using standardized in-house protocols and expanded in standard fibroblast culture medium. Additional fibroblast samples were obtained from INSERM and the Coriell Biorepository. In total, 5 different disease samples from 7 different patients were obtained (Table 1). Moloney murine leukemia virus-derived vectors, each containing the coding sequences of 1 of the 4 human genes OCT4, SOX2, c-Myc, and KLF4, and the corresponding viral particles were generated by Vectalys and used to infect the fibroblasts at MOI 10 as originally described by Yamanaka and colleagues and as we also recently described $(13,30)$. Once derived, human iPS cells were cultured in standard human ES cell culture conditions (KSR; Gibco, Invitrogen) plus FGF2 (4 ng/ml; R\&D Systems Inc.) on plates containing irradiated mouse feeders.

$R N A$ extraction and real-time PCR. Total RNAs were extracted from human iPS cells or differentiated progenitors using the RNeasy Mini Kit (Qiagen). Each sample was treated with RNase-Free DNase (Qiagen) to avoid DNA contamination. For each sample, $0.6 \mu \mathrm{g}$ of total RNA was reverse transcribed using Superscript II Reverse Transcriptase (Invitrogen). Real-time PCR reaction mixtures were prepared per the SensiMiX protocol (Quantace), then denatured at $94^{\circ} \mathrm{C}$ for $5 \mathrm{~min}$ utes and cycled at $94^{\circ} \mathrm{C}$ for 30 seconds, $60^{\circ} \mathrm{C}$ for 30 seconds, and $72^{\circ} \mathrm{C}$ for 30 seconds, followed by a final extension at $72^{\circ} \mathrm{C}$ for 10 minutes after completion of 40 cycles. Primer sequences were as described elsewhere (16). Real-time PCR reactions were performed using a Stratagene $\mathrm{Mx} 3005 \mathrm{P}$ in triplicate and normalized to porphobilinogen deaminase (PBGD) in the same run. Quantitative PCR data are presented as the mean of 3 independent experiments; error bars indicate SEM. Primers used for Real Time PCR analyses are shown in Table 2. 
Immunofluorescence. Human iPS cells or their differentiated progenitors were fixed for 20 minutes at $4{ }^{\circ} \mathrm{C}$ in $4 \%$ paraformaldehyde and then washed 3 times in PBS. Cells were incubated for 20 minutes at room temperature in PBS containing $10 \%$ donkey serum (Serotec Ltd.) and subsequently incubated overnight at $4{ }^{\circ} \mathrm{C}$ with the following primary antibodies, diluted in $1 \%$ donkey serum in PBS: Oct-4 (1:100; Abcam ab18976), Sox2 (1:100; Abcam ab15830), Brachyury (1:100; Abcam ab20680 or R\&D Systems Inc.), Sox17 (R\&D Systems Inc.), FoxA2 (1:50; Abcam ab5074), GATA4 (1:250; Santa Cruz Biotechnology Inc.), GATA6 (1:200; Abcam ab22600 or Santa Cruz Biotechnology Inc.), CXCR4 (1:100; R\&D Systems Inc. or BD Biosciences - Pharmingen), CK18 (1:50; Dako), CK19 (1:50; Dako), albumin (1:100; R\&D1455), alpha fetoprotein (AFP; 1:300; Dako A008), and $\alpha_{1}$-antitrypsin (AAT; 1:100; SigmaAldrich A0608). Cells were then washed 3 times in PBS and incubated with Texas Red or FITC-conjugated anti-mouse IgG (Sigma-Aldrich; 1:200 in 1\% donkey serum in PBS) or rabbit IgG (Jackson Laboratory; 1:400 in donkey serum in PBS) or goat IgG (Jackson Laboratory; 1:400 in donkey serum in PBS) for 2 hours at room temperature. Unbound secondary antibody was removed by 3 washes in PBS. Hoechst 33258 was added to the first wash (1:10,000; Sigma-Aldrich). For lipid visualization, a lipid-specific stain borondipyrromethene (BODIPY 493/503; Invitrogen D-3922) was used.

Teratomas. Human iPS cells were harvested mechanically immediately prior to implantation, and approximately $10^{6}$ cells were inoculated beneath the testicular capsule of 8-week-old C.B.-17/GbmsTac-scidbgDFN7 male mice (Taconic M\&B) housed and maintained at $20^{\circ} \mathrm{C}-24^{\circ} \mathrm{C}, 50 \%$ room humidity, in a 14-hour light, 10 -hour dark cycle with food and water ad libitum. The mice were sacrificed after 60 days, and the injected testes were cut into equal pieces using a razor blade. The material was fixed overnight in $4 \%$ neutral buffered formaldehyde, and dehydrated through a graded series of alcohols to xylene. The tissue was embedded in paraffin and serially sectioned at $5 \mu \mathrm{m}$, followed by $\mathrm{H} \& \mathrm{E}$ staining and characterization. A human origin of the selected areas was verified by FISH (human-specific probes, CEP XY; Vysis Inc.). The experiments were performed with permission from the Regional Committee for Animal Experimentation (Stockholm, Sweden; Dnr N107/06).

Karyotype analysis. Human iPS cells were grown to confluence on $10-\mathrm{cm}$ dishes, then harvested and metaphase spreads obtained by the Cambridge University Hospitals Cytogenetics diagnostics laboratory.

Differentiation of human iPS cells to hepatocytes. Human iPS cells were passaged using $5 \mathrm{mg} / \mathrm{ml}$ collagenase IV/Dispase (0.1\%; Gibco, Invitrogen) 1:1 $(\mathrm{v} / \mathrm{v}) \mathrm{mix}$, then transferred onto plates precoated with FBS in CDM-PVA or in plates precoated with human fibronectin, as previously described (16). For the first following day, cells were grown in CDM-PVA supplemented

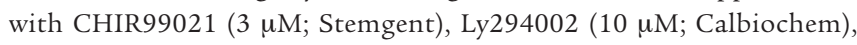
Activin (100 ng/ml; R\&D Systems), FGF2 (40 ng/ml; R\&D Systems), and BMP4 (10 ng/ml; R\&D Systems) to drive differentiation of human iPS cells into primitive streak like cells. The next day, the resulting cells were grown in CDM-PVA supplemented with Ly294002 (10 $\mu \mathrm{M}$; Calbiochem), Activin (100 ng/ml); FGF2 (40 ng/ml; R\&D Systems), and BMP4 (10 ng/ml; R\&D Systems) to drive their differentiation toward definitive endoderm. On the third day, the basal medium was changed to RPMI 1640 (Gibco, Invitrogen) and supplemented with Activin (100 ng/ml; R\&D Systems), FGF2 ( $40 \mathrm{ng} / \mathrm{ml} ; \mathrm{R} \& \mathrm{D}$ Systems), and B27 to obtain anterior definitive endoderm cells. To induce hepatic endoderm, anterior definitive endoderm cells were then cultured for 5 days in the presence of RPMI 1640 (Gibco, Invitrogen) supplemented with Activin ( $50 \mathrm{ng} / \mathrm{ml}$; R\&D Systems). Finally, to mature the resulting hepatic progenitors, cells were grown in a CMRL/Hepatozyme (Invitrogen) basal medium supplemented by HGF (20 $\mu \mathrm{g} / \mathrm{ml}$; Peprotech) and Oncostatin-M (10 $\mu \mathrm{g} / \mathrm{ml}$; R\&D Systems).

Flow cytometry. For detection of albumin-positive cells, adherent cells at the end of the hepatocyte differentiation protocol were washed twice in $\mathrm{PBS}$ and then incubated for 20 minutes at $37^{\circ} \mathrm{C}$ in cell dissociation buffer
(Invitrogen). Cells were dissociated by gentle pipetting and resuspended at approximately $0.1-1 \times 10^{5}$ cells $/ \mathrm{ml}$ in PBS plus $3 \%$ normal goat serum containing $0.1 \%$ azide (Serotec Ltd.) and $0.1 \%$ Triton-X. Cells were then incubated for 40 minutes at $4{ }^{\circ} \mathrm{C}$ with primary mouse anti-human albumin antibody (1:100; R\&D Systems 1455$)$ or mouse IgG isotype control (BD Biosciences - Pharmingen). Cells were then analyzed by a FACSCalibur machine (BD Biosciences). The number of albumin-positive cells was recorded as the average from 3 separate experiments.

Subcellular fractionation using iodixanol-stepped gradient and endoglycosidase $H$ digestion. Disease-specific human iPS cell-derived hepatocytes were grown in 6-well plates and harvested using a cell scraper. Cells were then mechanically disrupted by repeated passage over a ball bearing homogenizer. The cell suspension was centrifuged at $3,000 \mathrm{~g}$ for 5 minutes at $4^{\circ} \mathrm{C}$, and the supernatant was diluted to a final concentration of $35 \%$ OptiPrep (Axis-Shield) and transferred to a new centrifuge tube. $2 \mathrm{ml} \mathrm{30 \%} \mathrm{OptiPrep} \mathrm{and} 1 \mathrm{ml}$ 0\% OptiPrep were carefully layered sequentially on top of the supernatant, and the tube was spun at 70,000 $\mathrm{g}$ for 2 hours at $4^{\circ} \mathrm{C}$. The liquid interface formed between the 2 bottom layers was carefully aspirated and again spun at $100,000 \mathrm{~g}$ for 45 minutes at $4{ }^{\circ} \mathrm{C}$. The subsequent pellet formed was resuspended in $50 \mu \mathrm{l}$ buffer and labeled as the microsomal fraction. For endoglycosidase $\mathrm{H}$ [EC 3.2.1.96, glycopeptide-D-mannosyl-N4-(N-acetyl-D-glucosaminyl)2-asparagine 1,4-N-acetyl-b-glucosaminohydrolase] digestion, microsomal cellular fractions were digested with $500 \mathrm{U}$ endoglycosidase $\mathrm{H}$ enzyme (Boehringer Mannheim) for 3 hours at $37^{\circ} \mathrm{C}$, then analyzed as detailed below.

SDS-PAGE and Western blot analysis. Samples of $30 \mu \mathrm{l}$ were mixed with $10 \mu \mathrm{l}$ $4 \times$ loading buffer containing $10 \%(\mathrm{v} / \mathrm{v}) \beta$-mercaptoethanol and $4 \%(\mathrm{w} / \mathrm{v})$ SDS and analyzed by $8 \%(\mathrm{w} / \mathrm{v})$ acrylamide SDS-PAGE. The proteins were transferred from the gels onto Immobilon P membrane (Millipore Corp.) at $200 \mathrm{~mA}$ for 2 hours for Western blot analysis. $20 \%(\mathrm{v} / \mathrm{v})$ methanol was added to the transfer buffer. After transfer, the membrane was washed in PBT (PBS plus 0.1\% [v/v] Tween 20) and blocked overnight in PBT plus 5\% $(\mathrm{w} / \mathrm{v})$ dried skim milk powder (PBT-milk). The following day, the membrane was incubated with anti- $\alpha_{1}$-antitrypsin antibody diluted 1:10,000 in PBT-milk for 1 hour, washed 6 times for 5 minutes with PBT, and then incubated with 1:100,000 anti-mouse IgG-HRP antibody in PBT-milk for 1 hour. The membrane was washed a further 6 times for 5 minutes with PBT and 15 minutes in PBS before developing using the ECL Super Signal West Femto maximum sensitivity substrate (Pierce) and exposed to film.

ELISA for $\alpha_{1}$-antitrypsin. High binding surface Costar 96-well plates (Corning) were coated overnight with affinity-purified rabbit polyclonal antibodies against $\alpha_{1}$-antitrypsin (Abcam ab31657) at $2 \mu \mathrm{g} / \mathrm{ml}$ in carbonate/bicarbonate buffer $\left(\mathrm{Na}_{2} \mathrm{CO}_{3} / \mathrm{NAHCO}_{3}, \mathrm{pH} 9.5\right)$. After washing $(0.9 \%[\mathrm{w} / \mathrm{v}] \mathrm{NaCl}$ and $0.05 \%[\mathrm{v} / \mathrm{v}]$ Tween 20$)$, the plates were blocked for 2 hours in blocking buffer (PBS, $0.25 \%$ [w/v] BSA, 0.05\% [v/v] Tween 20). Samples (culture medium or cells lysed in $50 \mu \mathrm{l}$ Nonidet lysis buffer $-150 \mathrm{mM} \mathrm{NaCl} ; 50 \mathrm{mM}$ Tris-Cl, pH 7.5; 1\% [v/v] Nonidet P-40) and standards (plasma purified M or $Z \alpha_{1}$-antitrypsin) were diluted in blocking buffer, and $50 \mu \mathrm{l}$ was added to each well and then incubated for 2 hours. After washing, the wells were incubated with either 9C5 or 2C1 monoclonal antibodies $(1 \mu \mathrm{g} / \mathrm{ml}$ diluted in blocking buffer) and incubated for 2 hours. Bound monoclonal antibodies were detected with rabbit anti-mouse IgG HRP-labeled antibody (1:20,000; Sigma-Aldrich) for 1 hour. The reaction was developed with TMB liquid substrate (Sigma-Aldrich) for 10 minutes in the dark, and the reaction was stopped with $1 \mathrm{M} \mathrm{H}_{2} \mathrm{SO}_{4}$. Absorbance was read at $450 \mathrm{~nm}$ on a Thermomax microplate reader (Molecular Devices). For the proteasome blocking assay, cells were grown in 6-well plates, and MG132 (AG Scientific) diluted $1: 10,000$ was added to the culture medium 16 hours prior to harvest (i.e., overnight). Control samples had equal volumes of PBS added to them.

ELISA for albumin. Cell culture medium collected over 24 hours was analyzed in triplicate by the Cambridge University Hospitals Biochemical 
diagnostics laboratory using an in-house human albumin specific ELISA kit (BioSupply UK). Values were expressed as nanograms per million cells per milliliter culture medium.

Cytochrome $P 450$ activity. Cyp3A4 activity assay was measured in triplicate using the P450-Glo assay kit (Promega) according to the manufacturer's instructions. Cytochrome activity was then analyzed using a P450-GloMax 96 microplate luminometer (Promega).

PAS staining. PAS staining was carried out on cells in triplicate using a kit (Sigma-Aldrich 395B-1KT) according to the manufacturer's instructions. Diastase digestion was subsequently performed to confirm that positive staining was due to the presence of glycogen.

Transmission EM. Cells were rinsed briefly in $0.9 \% \mathrm{NaCl}$ and fixed for 2 hours in $4 \%$ glutaraldehyde at $4{ }^{\circ} \mathrm{C}$. Cells were then scraped from the plates under fix and resuspended by rinsing in $0.1 \mathrm{M}$ PIPES. Analysis was performed by transmission EM.

Uptake of LDL. The Dil-LDL staining kit was purchased from Stoughton, and the assay was performed according to the manufacturer's instructions. FACS analysis was performed comparing Dil incorporation in FH diseasespecific human iPS cell hepatocytes with that in control HepG2 cells.

GFP reporter. Cells were transduced with the APOA-II-GFP lentivector as previously described (16) and examined by microscopy.

Metabolic enzyme response to glucagon stimulation. Disease-specific human iPS cell-derived hepatocytes were incubated for 6 hours in serum-free, highglucose DMEM supplemented with $2 \mathrm{mM}$ L-glutamine, $100 \mathrm{U} / 1$ penicillin, $100 \mu \mathrm{g} / \mathrm{ml}$ streptomycin, and $0.5 \%$ BSA (all from Sigma-Aldrich). Cells were stimulated with $100 \mathrm{nM}$ glucagon hydrochloride (Novo Nordisk) or PBS (SigmaAldrich) as a negative control. Total RNA was harvested using the RNeasy Kit (Qiagen) at 0, 1, 2, or 3 hours after stimulation and purified per the manufacturer's guidelines. Reverse transcription was performed on $1 \mu \mathrm{g}$ RNA in a $25-\mu \mathrm{l}$ reaction mixture containing $200 \mathrm{U}$ Moloney murine leukemia virus reverse transcriptase, $500 \mathrm{ng}$ random primers, and $0.5 \mathrm{mM}$ deoxynucleotide triphos- phates (all from Promega) per the manufacturer's guidelines. cDNA was subjected to real-time quantitative PCR on an ABI7900 detection system (Applied Biosystems) using Taqman PCR Mastermix (Applied Biosystems) and genespecific forward and reverse primers and fluorogenic probes. All results were normalized to human $36 B 4$ as a reference gene. Primers and probes for PEPCK (Hs00159918_m1), G6P(Hs00609178_m1), and IGFBP1 (Hs00426285_m1) were purchased as pre-made stocks from Applied Biosystems. Oligonucleotides for 36B4 were designed in house and synthesized by Sigma-Aldrich (forward, 5'-GCAGATCCGCATGTCCCTT-3'; reverse, 5'-TGTTTTCCAGGTGCCCTCG-3'; Probe, 5' -[JOEE]AGGCTGTGGTGCTGATG[TAMRA]-3').

\section{Acknowledgments}

This work was funded by the Wellcome Trust, MRC, and the Cambridge Hospitals National Institute for Health Research Biomedical Research Center. S.T. Rashid is a Wellcome Trust Clinical Training Fellow, S.J. Marciniak is an MRC Clinician Scientist, R. Semple is a Wellcome Trust Clinician Scientist Fellow, and L. Vallier is an MRC Senior non clinical Fellow. S. Corbineau was supported by a grant from Ingecell, Pôle de compétitivité Medicen, Région Île-deFrance. We are grateful to Keith Burling (Clinical Biochemistry) and Joanne Staines (Clinical Cytogenetics) of Addenbrooke's Hospital for their help.

Received for publication March 25, 2010, and accepted in revised form July 14, 2010.

Address correspondence to: Ludovic Vallier or S. Tamir Rashid, Laboratory for Regenerative Medicine, West Forvie Building, Robinson Way, University of Cambridge, Cambridge CB2 0SZ, United Kingdom. Phone: 44.1223.747489; Fax: 44.1223.763350; E-mail: lv225@cam.ac.uk (L.Vallier); str29@cam.ac.uk (S.T. Rashid).
1. Saha K, Jaenisch R. Technical challenges in using human induced pluripotent stem cells to model disease. Cell Stem Cell. 2009;5(6):584-595.

2. Park IH. Disease-specific induced pluripotent stem cells. Cell. 2008;134(5):877-886.

3. Maehr R, et al. Generation of pluripotent stem cells from patients with type 1 diabetes. Proc Natl Acad Sci U S A. 2009;106(37):15768-15773.

4. Dimos JT. Induced pluripotent stem cells generated from patients with ALS can be differentiated into motor neurons. Science. 2008;321(5893):1218-1221.

5. Lee $\mathrm{G}$, et al. Modelling pathogenesis and treatment of familial dysautonomia using patient-specific iPSCs. Nature. 2009;461(7262):402-406.

6 . Ebert AD. Induced pluripotent stem cells from a spinal muscular atrophy patient. Nature. 2009; 457(7227):277-280.

7. Balch WE, Morimoto RI, Dillin A, Kelly JW. Adapting proteostasis for disease intervention. Science. 2008;319(5865):916-919.

8. Pan S, et al. Single nucleotide polymorphism-mediated translational suppression of endoplasmic reticulum mannosidase I modifies the onset of end-stage liver disease in alpha1-antitrypsin deficiency. Hepatology. 2009;50(1):275-281.

9. Perlmutter DH. Autophagic disposal of the aggregation-prone protein that causes liver inflammation and carcinogenesis in [alpha]-1-antitrypsin deficiency. Cell Death Differ. 2008;16(1):39-45.

10. Enns GM, Millan MT. Cell-based therapies for metabolic liver disease. Mol Genet Metab. 2008; 95(1-2):3-10.

11. Fisher RA, Strom SC. Human hepatocyte transplantation: worldwide results. Transplantation. 2006;82(4):441-449.

12. Guillouzo A, Guguen-Guillouzo C. Evolving concepts in liver tissue modeling and implications for in vitro toxicology. Expert Opin Drug Metab Toxicol. 2008;4(10):1279-1294

13. Takahashi K, Yamanaka S. Induction of pluripotent stem cells from mouse embryonic and adult fibroblast cultures by defined factors. Cell. 2006;126(4):663-676.

14. Brons IG, et al. Derivation of pluripotent epiblast stem cells from mammalian embryos. Nature. 2007;448(7150):191-195.

15. Chin $\mathrm{MH}$, et al. Induced pluripotent stem cells and embryonic stem cells are distinguished by gene expression signatures. Cell Stem Cell. 2009;5(1):111-123.

16. Touboul T, et al. Generation of functional hepatocytes from human embryonic stem cells under chemically defined conditions which recapitulate liver development. Hepatology. 2010; 51(5):1754-1765.

17. Gooptu B, Lomas DA. Conformational pathology of the serpins: themes, variations, and therapeutic strategies. Annu Rev Biochem. 2009;78:147-176.

18. Perlmutter DH. Pathogenesis of chronic liver injury and hepatocellular carcinoma in alpha-1-antitrypsin deficiency. Pediatr Res. 2006;60(2):233-238.

19. Miranda E, et al. A novel monoclonal antibody to characterize pathogenic polymers in liver disease associated with alpha(1)-antitrypsin deficiency [published online ahead of print May 14, 2010]. Hepatology. doi:10.1002/hep. 23760.

20. Rader DJ, Cohen J, Hobbs HH. Monogenic hypercholesterolemia: new insights in pathogenesis and treatment. J Clin Invest. 2003;111(12):1795-1803.

21. Shieh J-J, et al. The molecular basis of glycogen storage disease type 1a.J Biol Chem. 2002;277(7):5047-5053.

22. Salavert A, Iynedjian PB. Regulation of phosphoenolpyruvate carboxykinase (GTP) synthesis in rat liver cells. Rapid induction of specific mRNA by glucagon or cyclic AMP and permissive effect of dexa- methasone. J Biol Chem. 1982;257(22):13404-13412.

23. Dentin R, et al. Insulin modulates gluconeogenesis by inhibition of the coactivator TORC2. Nature. 2007;449(7160):366-369.

24. Piitulainen E, Carlson J, Ohlsson K, Sveger T. Alpha1-antitrypsin deficiency in 26-year-old subjects: lung, liver, and protease//protease inhibitor studies. Chest. 2005;128(4):2076-2081.

25. Wu Y, Whitman I, Molmenti E, Moore K, Hippenmeyer P, Perlmutter DH. A lag in intracellular degradation of mutant [alpha]1-antitrypsin correlates with the liver disease phenotype in homozygous PiZZ a1-antitrypsin deficiency. Proc Natl Acad Sci US A. 1994;91(19):9014-9018.

26. Cabral CM, Choudhury P, Liu Y, Sifers RN. Processing by endoplasmic reticulum mannosidases partitions a secretion-impaired glycoprotein into distinct disposal pathways. J Biol Chem. 2000; 275(32):25015-25022.

27. Cabral CM, Liu Y, Moremen KW, Sifers RN. Organizational diversity among distinct glycoprotein endoplasmic reticulum-associated degradation programs. Mol Biol Cell. 2002;13(8):2639-2650.

28. Teckman JH, Burrows J, Hidvegi T, Schmidt B, Hale $\mathrm{PD}$, Perlmutter $\mathrm{DH}$. The proteasome participates in degradation of mutant $\hat{I} \pm 1$-antitrypsin $Z$ in the endoplasmic reticulum of hepatoma-derived hepatocytes. J Biol Chem. 2001;276(48):44865-44872.

29. Qu D, Teckman JH, Omura S, Perlmutter DH. Degradation of a mutant secretory protein, alpha 1 -antitrypsin $Z$, in the endoplasmic reticulum requires proteasome activity. J Biol Chem. 1996; 271(37):22791-22795.

30. Vallier L, et al. Signalling pathways controlling pluripotency and early cell fate decisions of human induced pluripotent stem cells. Stem Cells. 2009; 27(11):2655-2566. 